\title{
The Freshwater Information Platform: a global online network providing data, tools and resources for science and policy support
}

\author{
Astrid Schmidt-Kloiber (D) V Vanessa Bremerich • Aaike De Wever • \\ Sonja C. Jähnig · Koen Martens · Jörg Strackbein • Klement Tockner • \\ Daniel Hering
}

Received: 4 March 2019/Revised: 25 May 2019/Accepted: 28 May 2019/Published online: 6 June 2019

(C) The Author(s) 2019

\begin{abstract}
Freshwaters are among the most complex, dynamic, and diverse ecosystems globally. Despite their small share of the earth's surface (less than 1\%) they are home to over $10 \%$ of all known animal species. Biodiversity decrease in general and freshwater biodiversity decline in particular have recently received increasing attention, and various policy instruments are now targeting the conservation, protection and enhancement of biodiversity and associated ecosystem services. Surveillance programs as
\end{abstract}

Handling editor: Luigi Naselli-Flores

A. Schmidt-Kloiber $(\square)$

Institute of Hydrobiology and Aquatic Ecosystem

Management, University of Natural Resources and Life

Sciences, BOKU Vienna, Gregor Mendel Straße 33,

1180 Vienna, Austria

e-mail: ask@boku.ac.at

V. Bremerich · S. C. Jähnig · K. Tockner

Department of Ecosystem Research, Leibniz-Institute of Freshwater Ecology and Inland Fisheries (IGB),

Müggelseedamm 301, 12587 Berlin, Germany

A. De Wever

Research Institute for Nature and Forest (INBO),

Havenlaan 88 bus 73, 1000 Brussels, Belgium

K. Martens

Royal Belgian Institute of Natural Sciences, Vautierstraat

29, 1000 Brussels, Belgium well as a variety of research projects have been producing a tremendous amount of freshwater-related information. Though there have been various attempts to build infrastructures for online collection of such data, tools and reports, they often provide only limited access to resources that can readily be extracted for conducting large scale analyses. Here, we present the Freshwater Information Platform, an open system of relevant freshwater biodiversity-related information. We provide a comprehensive overview of the platform's core components, highlight their values, present options for their use, and discuss future

\author{
K. Martens \\ Department of Biology, University of Ghent, K.L. \\ Ledeganckstraat 35, 9000 Ghent, Belgium \\ J. Strackbein · D. Hering \\ Department of Aquatic Ecology, Faculty of Biology, \\ University of Duisburg-Essen, Universitätsstraße 5, \\ 45141 Essen, Germany \\ K. Tockner \\ Austrian Science Fund, Haus der Forschung, Sensengasse \\ 1, 1090 Vienna, Austria \\ K. Tockner \\ Institute of Biology, Freie Universität Berlin, Königin- \\ Luise-Str. 1-3, 14195 Berlin, Germany
}


developments. This is complemented by information on the platform's current management structure, options for contributing data and research results and an outlook for the future.

Keywords Inland waters $\cdot$ Knowledge base $\cdot$ Open access - (Meta-)data publishing - Biodiversity ·

Rivers · Lakes

\section{Introduction}

Freshwaters are among the most complex, dynamic, and diverse ecosystems globally. Despite their small share of the earth's surface (i.e. less than $1 \%$ ), ten per cent of all animals, one-third of all vertebrates, and $40 \%$ of all fish species are restricted in their occurrence to freshwaters (Dudgeon et al., 2006; Strayer \& Dudgeon, 2010; Darwall et al., 2018). At the same time, freshwaters are among the most threatened ecosystems worldwide, with biodiversity declining much faster than in marine and terrestrial realms (Darwall et al., 2009; Garcia-Moreno et al., 2014). The latest Freshwater Index of the Living Planet Index emphasised the rapid erosion of freshwater biodiversity, with an 83\% reduction since 1970 (WWF, 2018). Reid et al. (2018) documented twelve threats to freshwater biodiversity that either emerged since 2006 or have intensified throughout the Anthropocene.

Biodiversity decrease in general and freshwater biodiversity decline in particular have recently received increasing attention, and various policy instruments are now targeting the conservation, protection and enhancement of biodiversity and associated ecosystem services. Globally, the United Nations Conference on Environment and Development universally acknowledged the importance of biodiversity and ecosystem health, leading to the Convention on Biological Diversity (CBD). At the global scale, the CBD is complemented, amongst others, by the Ramsar Convention, the Millenium Ecosystem Assessment, the Aichi Biodiversity Targets, the UN Sustainable Development Goals, and the UN Draft resolution on addressing water pollution to protect and restore water-related ecosystems.

In Europe, several directives and strategies are targeting freshwater life either through the protection of biodiversity in more general terms (Habitats
Directive, EU Biodiversity Strategy 2020) or through the enhancement of water quality and other ecosystem services related to water (Water Framework Directive, Blueprint to Safeguard Europe's Water Resources). Both globally and in Europe, the adoption of these policy instruments and initiatives was accompanied by comprehensive scientific and administrative efforts to generate data, to build monitoring tools and to assess the status of species and ecosystems.

As a result, freshwaters are now among the most intensively surveilled ecosystems worldwide. Biodiversity-related data are frequently collected to monitor the ecological status of freshwaters, and numerous research projects have addressed freshwater ecosystem assessment, management and restoration. However, the data, tools and reports generated, both by scientific projects and by monitoring activities, remain scattered and are not centrally collected. Even in Europe, where the Water Framework Directive and Habitats Directive have led to intense and widely harmonised monitoring efforts, the original data remain in the responsibilities of the individual countries and are therefore not centrally stored.

Collaborative research projects involving several institutions, such as projects funded by the European Commission, usually develop individual websites for disseminating aims and results to other scientists and to a wider public. Hence, numerous projects addressing freshwaters have generated websites, tools, databases and other products, many of which are originally intended for long-term use. However, these infrastructures are often not maintained after the termination of the project and the content is rarely further adapted or extended, simply because there is a lack of sustainable funding and commitment. Additionally, the websites of related research projects have been developed in isolation; therefore, valuable data and information remain scattered and dispersed. Consequently, for freshwater researchers and other users, it is challenging to gain an overview of the variety of projects and their specific outputs and products.

There have been various attempts to build platforms for collecting biodiversity data, e.g. for mammals (Ceballos \& Ehrlich, 2006), birds (Stattersfield \& Capper, 2000), amphibians (Stuart et al., 2004) and dragon- and damselflies (Clausnitzer et al., 2009). The Freshwater Animal Diversity Assessment (FADA) initiative provided the first comprehensive global 
overview of freshwater species (Balian et al., 2007), and the Global Biodiversity Information Facility (GBIF) hosts occurrence records for all types of ecosystems, including freshwaters. These platforms gain in relevance as data, information and knowledge generated through public funding are considered a common good (i.e. Open Science). Furthermore, there is a demand of peers for checking the quality and reproducibility of research outcomes to guarantee scientific integrity. Therefore, many funding organisations already require data management plans that define all data-related processes within and after projects (Michener, 2015). Data repositories as well as information and knowledge platforms are the fundamental base for data dissemination according to the FAIR principles (Findable, Accessible, Interoperable, Reusable) in Open Science. In a recent review, Schmidt-Kloiber \& de Wever (2018) provide an overview of the most relevant freshwater information sources according to the following categories: general data portals, biodiversity-related data sources (including occurrence, taxonomy, traits, genetic and molecular data), and spatial data sources. However, even data centres supported by the European Commission (e.g. WISE, BISE, EEA Data Centres) provide limited access to resources that can readily be extracted for conducting large scale analyses.

Here, we present the Freshwater Information Platform (FIP, www.freshwaterplatform.eu) that was initialised in 2015 and extended ever since with the aim of providing access to primary data, metadata, reports and tools on freshwater biodiversity, primarily resulting from EU-funded research projects. We briefly introduce the platform's structure and contents as well as future plans for extending the Freshwater Information Platform as a joint data, information and knowledge infrastructure for European and international projects and programs.

The FIP started as a project website of the EUfunded BioFresh project ("Biodiversity of freshwater ecosystems: status, trends, pressures and conservation priorities"; http://freshwaterbiodiversity.eu) that aimed at investigating the status, trends, pressures and conservation priorities of freshwater biodiversity and its related ecosystem services. To overcome the identified shortcomings of websites' lifetimes as well as of scattered data and information, the BioFresh consortium decided to not only maintain this platform after the project's termination, but to extend its scope from biodiversity issues to various aspects related to freshwater ecology, management and research. The FIP is designed for long-term use and maintenance, mainly enabled through the commitments of four research institutions, and serves as a single gateway for scientists, water managers, policy-makers, conservationists, NGOs and the interested public to directly access freshwater ecosystem-related data and information.

\section{Contents of the Freshwater Information Platform}

The FIP is an open system of relevant freshwaterrelated information components, organised as "boxes" on the webpage. Currently, it offers twelve basic components (Table 1) that can be amended if necessary. An additional "box" on the website is open for recent developments and news. Here, we provide a comprehensive overview of the core components, highlight their values, present options for their use, and discuss future developments (Fig. 1).

Freshwater Metadatabase and Freshwater Metadata Journal

The value of metadata-i.e. the who, why, what, when and where of a given dataset-in ecological sciences has been well recognised (e.g. Fegraus et al., 2005; Michener, 2006; Michener \& Jones, 2012), and compiling such information is getting common in the scientific community. The Global Biodiversity Information Facility (GBIF), for example, collates and centralises not only primary biodiversity data but also offers standards and tools for (meta)data collection, e.g. the GBIF Integrated Publishing Toolkit (IPT) or the specific GBIF metadata profile.

Efforts to provide an overview of primary freshwater-related datasets led to the establishment of the Freshwater Metadatabase (Schmidt-Kloiber et al., 2012). In its latest version, the Freshwater Metadatabase provides a multi-lingual web interface, offering in addition to the default English version, German, French and Dutch as languages for entering and searching of data. Currently the database holds 
Table 1 Components of the FIP

\begin{tabular}{|c|c|}
\hline FIP component and web address & Description \\
\hline $\begin{array}{l}\text { Freshwater Metadata Journal and Metadatabase } \\
\text { www.freshwatermetadata.eu } \\
\text { www.freshwaterjournal.eu }\end{array}$ & $\begin{array}{l}\text { Links to the Freshwater Metadata Journal and Metadatabase providing general } \\
\text { information on freshwater datasets }\end{array}$ \\
\hline $\begin{array}{l}\text { Freshwater Biodiversity Data Portal } \\
\text { http://data.freshwaterbiodiversity.eu }\end{array}$ & $\begin{array}{l}\text { Links to the Freshwater Biodiversity Data Portal hosting freshwater occurrence } \\
\text { data }\end{array}$ \\
\hline $\begin{array}{l}\text { Global Freshwater Biodiversity Atlas } \\
\text { http://atlas.freshwaterbiodiversity.eu }\end{array}$ & $\begin{array}{l}\text { Links to the Global Freshwater Biodiversity Atlas providing thematic maps on } \\
\text { freshwater biodiversity and related topics }\end{array}$ \\
\hline $\begin{array}{l}\text { Freshwater Species Trait Database } \\
\text { www.freshwaterecology.info }\end{array}$ & $\begin{array}{l}\text { Links to the freshwaterecology.info database providing unified, standardised and } \\
\text { codified information about the ecological preferences and biological traits of } \\
\text { more than 20,000 European freshwater organisms }\end{array}$ \\
\hline $\begin{array}{l}\text { Research Deliverables } \\
\text { http://www.freshwaterplatform.eu/index.php/ } \\
\text { research-deliverables.html }\end{array}$ & $\begin{array}{l}\text { Provides a collection of deliverables from a variety of freshwater-related } \\
\text { research projects }\end{array}$ \\
\hline $\begin{array}{l}\text { Freshwater Tools } \\
\text { http://www.freshwaterplatform.eu/index.php/ } \\
\text { tools.html }\end{array}$ & $\begin{array}{l}\text { Provides a collection of freshwater-related tools for analyses, modelling, stressor } \\
\text { diagnosis and mitigation, assessment and publishing }\end{array}$ \\
\hline $\begin{array}{l}\text { Freshwater Resources } \\
\text { http://www.freshwaterplatform.eu/index.php/ } \\
\text { resources.html }\end{array}$ & $\begin{array}{l}\text { Provides a collection of resources, e.g. a glossary, a selection of key journals, } \\
\text { training and education materials including videos etc. }\end{array}$ \\
\hline $\begin{array}{l}\text { Freshwater Policies } \\
\text { http://www.freshwaterplatform.eu/index.php/ } \\
\text { overview.html }\end{array}$ & $\begin{array}{l}\text { Provides a collection of policy briefs and links to relevant freshwater-related } \\
\text { policies }\end{array}$ \\
\hline $\begin{array}{l}\text { Freshwater Information Systems } \\
\text { http://www.freshwaterplatform.eu/index.php/ } \\
\text { freshwater-information-systems.html }\end{array}$ & $\begin{array}{l}\text { Provides a collection of further useful information systems supporting } \\
\text { freshwater-related research }\end{array}$ \\
\hline $\begin{array}{l}\text { Freshwater Networks and Projects } \\
\text { http://www.freshwaterplatform.eu/index.php/ } \\
\text { networks-projects.html }\end{array}$ & $\begin{array}{l}\text { Gives an overview of global and European research initiatives and links to past } \\
\text { and ongoing research projects }\end{array}$ \\
\hline $\begin{array}{l}\text { Freshwater Blog } \\
\text { https://freshwaterblog.net }\end{array}$ & $\begin{array}{l}\text { Links to the Freshwater Blog, featuring information about current topics in } \\
\text { freshwater research and management }\end{array}$ \\
\hline $\begin{array}{l}\text { Fact Sheets } \\
\text { http://www.freshwaterplatform.eu/index.php/ } \\
\text { fact-sheets.html }\end{array}$ & $\begin{array}{l}\text { Provides a collection of facts about freshwater research in a digestible format } \\
\text { including key messages in a brief and concise style }\end{array}$ \\
\hline "Open box" & Features recent developments and news \\
\hline
\end{tabular}

metadata of more than 300 publicly available datasets, presenting a variety of data types and covering regional to global ranges. Information on datasets can be exported as pdf- or eml-formats.

As data mobilisation is not always straightforward, Chavan \& Penev (2011) advertise “(meta)data papers" as a mechanism to incentivise data publishing. There is also evidence that online publication of research data benefits scientists (Costello, 2009). Following this idea, the "Freshwater Metadata
Journal" (FMJ) was established (Schmidt-Kloiber et al., 2014), which allows publishing information entered in the Freshwater Metadatabase as a journal article. All manuscripts are assigned digital object identifiers (DOI) and are made accessible on the FMJ website in open access, thereby making the dataset information citable and traceable, just like any other standard scientific paper. The simple publishing process of quotable papers serves as an incentive to make information on a dataset, and finally the dataset 


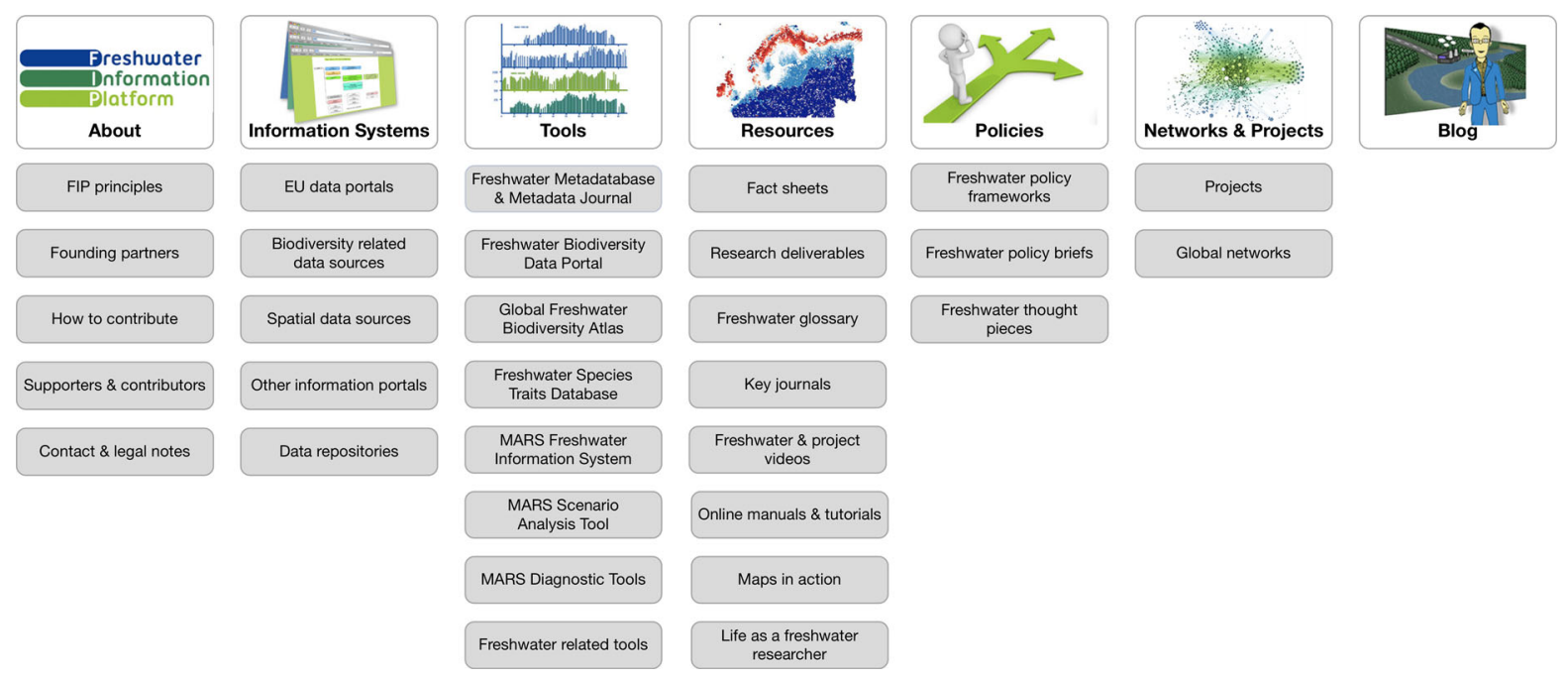

Fig. 1 Components of the FIP according to the main menu

itself, publicly available. By early 2019, the journal has published over 40 open access articles on a variety of freshwater datasets.

\section{Freshwater Biodiversity Data Portal}

The knowledge about species distributions and hotspots of endangerment is critical for setting conservation priorities to address the acute worldwide biodiversity crisis (Feeley \& Silman, 2011). It requires enormous efforts to access and unite widely dispersed biodiversity data and to establish open data publishing as a standard scientific practice (De Wever et al., 2012). Describing existing datasets in a public metadatabase such as the Freshwater Metadatabase is a first step in data mobilisation, but most large-scale analyses and modelling approaches require access to original data. Although datasets described in a metadatabase or in scientific papers could be individually requested, this is a time-consuming process, in particular for large-scale studies and if non-standard licenses are used (Desmet, 2013). While the use of GBIF data in scientific publications is steadily increasing, only a small proportion of GBIF data are related to freshwater ecosystems.

The "Freshwater Biodiversity Data Portal" was established during the BioFresh project to enable freshwater biodiversity data publishing and to increase the visibility of such data. Currently, it provides access to authoritative global species lists through FADA as well as to occurrence data mobilised during the project, through follow-up activities, and harvested from GBIF. Results can be displayed as either occurrence points or in density grids. A range of these data is being used in scientific publications supported by project members (e.g. Zagmajster et al., 2014; Tedesco et al., 2017) and other scientists, mostly related to modelling activities (e.g., van Vliet et al., 2013) or completion of databases (Gerovasileiou et al., 2016).

After the official end of BioFresh (April 2014) species occurrence data are now made available using the Integrated Publishing Toolkit (IPT) which exposes the data to the GBIF network. To create visibility for the published datasets, we are currently establishing a "Freshwater Network" on GBIF in close collaboration with the GBIF secretariat and the support of other freshwater focused initiatives including the "Alliance for Freshwater Life" and Freshwater BON (FWBON). The GBIF network page will provide a sustainable, lightweight solution for locating and viewing freshwater datasets and reduces the need to invest in a separate data portal offering this functionality specifically for freshwaters.

Global Freshwater Biodiversity Atlas

Online maps are both powerful exploratory and visualisation tools as well as an alternative interface for discovering information on the web (Kraak, 2004). 
In light of the exacerbating freshwater biodiversity crisis (Reid et al., 2018), it is essential to have spatially explicit information on global freshwater biodiversity and on stressor intensities available. The Global Freshwater Biodiversity Atlas aims to support policy-makers, water managers and scientists with an online, open-access and interactive gateway to key geographical information and spatial data on freshwater biodiversity, from local to global scales. Unlike other online atlases that focus on visualisation of occurrence points (e.g. the Atlas of Living Australia or Map of Life, Jetz et al., 2012; Belbin \& Williams, 2016), the Global Freshwater Biodiversity Atlas features maps originating from research projects and scientific publications.

Currently, the Atlas holds-overseen by an international scientific editorial board-a collection of over 50 interactive online maps dealing with the current and future state of freshwater biodiversity and ecosystems. It adopts a book-like structure allowing easy browsing through four thematic chapters: freshwater biodiversity, freshwater ecosystems, freshwater pressures and impacts, freshwater conservation and management. Each map is accompanied by a short article with further contextual background information and links to original publications. The interactive map interface allows users to switch between the maps and their layers easily, navigate and zoom within maps, and view additional information for each map feature. Unlike a conventional printed atlas, it is constantly expanded and updated as new maps and data become available. Maps of the Atlas and underlying data are widely used by other researchers to support their analysis or visualise their findings (e.g. Water Risk Filter, WWF, 2019; Tydecks et al., 2016; Cid et al., 2017).

To allow better documentation and description of the geodata contained in the Atlas, an advanced geodata management system is going to be implemented in future. This system is expected to additionally provide improved download capabilities, as well as web map services for re-use in other online applications.

\section{Freshwater Species Trait Database}

Species' biological traits and ecological preferences are important components to better understand distribution patterns, to help assessing and evaluating the status of freshwater ecosystems and to support biodiversity conservation. In Europe, environmental legislation, especially the Water Framework Directive (WFD) has placed aquatic organisms into a central position, as the composition of freshwater biota defines the status of surface water bodies, and thus determines the needs for restoration and associated investments. In Europe, the WFD has been the main driver for the development of ecological assessment systems in recent years, which often use ecological classifications as source for bioindication. Comprehensive databases compiling such species traits have a longer tradition in the terrestrial realm, e.g. TRY for plants (Kattge et al., 2011) or NodDB for fungi (Tedersoo et al., 2014) and Mycoflor for mycorrhiza (Bueno et al., 2017). For freshwater organisms a database mainly on genus level was available (Tachet et al., 2010) until the establishment of freshwaterecology.info (Schmidt-Kloiber \& Hering, 2015).

This online tool integrates various data sources into a comprehensive database of large-scale distribution patterns, biological traits and ecological preferences of freshwater species, including phytoplankton, diatoms, macrophytes, macro-invertebrates and fishes. The database hosts more than 21,000 European freshwater organisms and information about their specific ecology. Details about available parameters and classifications are listed in Schmidt-Kloiber \& Hering (2015). The database currently has more than 1,700 registered users and is applied in many studies dealing with a variety of research questions (some recent examples: de Brouwer et al., 2019; Fornaroli et al., 2019; Haase et al., 2019; Lorenz \& Wolter, 2019). The trait database is constantly expanded and amended.

\section{Freshwater Tools}

Following the needs of the WFD implementation, many research projects have developed predictive models, decision support systems and assessment systems to support freshwater ecosystem management. As an example, more than 300 assessment systems for different organism groups and water types are currently used in Europe (Birk et al., 2012) and the number of Decision Support Systems is most likely not lower. Similar to data on freshwater biodiversity, they are dispersed over different websites, many of which are not maintained once a project had been terminated. The "tools" component of the FIP provides access to a selection of tools under the FIP's 
administration that can either be used online via the portal's interface or through their dedicated webpages. Three of the tools were developed during the MARS project (Hering et al., 2015; Schinegger et al., 2018), mainly serving WFD compliant river basin management: (1) an Information System about managing aquatic ecosystems and water resources under multiple stress, featuring a selection tool among 21 frequently used modelling tools in catchment management (Chrzanowski \& Buijse, 2017); (2) a Diagnostic Tool, which is designed to identify the major stressors acting on a water body from ecological and environmental data (Lemm et al., 2019); and (3) a Scenario Analysis Tool, which provides modelled information on hydrology, nutrient emissions and several background data such as climate, land use and population density as well as the modelled probability to reach good ecological status under different future scenarios for 104,000 sub-catchments in Europe (Mack et al., 2019).

Additionally, the FIP provides a collection and gateway to a variety of other freshwater relevant tools divided into five categories (i.e. spatial/modelling tools, ecological assessment tools, literature analysis tools, R-packages and tools, GIS tools).

Information systems, research deliverables, fact sheets and other freshwater resources

In addition to metadata, original data, traits and tools hosted by the platform, the FIP provides access to a range of diverse distributed freshwater-related information. There are already several knowledge platforms on biodiversity-related data sources or spatial and taxonomical data that are critical for researchers. To easily access them, we have summarised these information systems in the component "Information Systems". We present general data portals (e.g. the EU-featured WISE and BISE data portals, the EEA data centre etc.), biodiversity-related data sources (including occurrence data, taxonomy, trait, gene and molecular data), spatial data sources, knowledge portals and data repositories often used by freshwater researchers.

The "Research Deliverables" component allows access to documents from finalised EU-funded research projects dealing with freshwater biodiversity (currently 15 projects). The projects are also represented and linked to in the "Freshwater Projects" component. The "Fact Sheets" component provides summaries of these projects. Other, more general resources-compiled in the component "Freshwater Resources"- are addressed to early-career scientists and the interested public, including a glossary of terms, a learning series ("How to..."), example maps from the Global Freshwater Biodiversity Atlas ("Maps in Action"), links to key journals in freshwater science as well as a series about freshwater researchers. The component is complimented by a series of short videos to engage a wider audience and make freshwater biodiversity science more comprehensible.

Freshwater policies and global networks

In the component "Freshwater Policies", we introduce the EU freshwater policy landscape to help scientists, NGOs, and the interested public to engage more actively in policies that affect freshwater biodiversity and ecosystems. In addition, this section collects "Policy Briefs" from freshwater-related, EU-funded research projects (currently 20 policy briefs). By summarising the key findings of these projects, policy briefs outline their implications for policy, offer support and provide recommendations for informed decisions. The complementary "Thought Pieces", are reflective articles exploring new ideas, posing questions, and thought-provoking arguments.

Additionally, we provide an overview of major global networks in the freshwater realm including the Alliance for Freshwater Life (AFL), the Alliance for Global Water Adaptation (AGWA), Conservation International (CI), the Freshwater Animal Diversity Assessment (FADA) project, Future Earth, the Global Biodiversity Information Facility (GBIF), GEO BON and the Freshwater Biodiversity Observation Network (FWBON), the Global Earth Observation System of Systems (GEOSS), the International Union for Conservation of Nature (IUCN), Wetlands International, Nature Conservancy, and the World Wildlife Fund (WWF). A key statement introduces each network and provides a link to the individual websites.

Freshwater Blog

Science communication aims at demonstrating how research contributes to innovation or societal challenges and their solutions as well as at justifying public expenses. While communication among scientists 
primarily involves publishing of papers, other means of communication are required for interaction with the general public. Electronic dissemination tools, e.g. blogs or social networking services such as Facebook or Twitter, are increasingly important to translate scientific results into a publicly understandable and easily readable language. As part of the FIP, the Freshwater Blog was started in June 2010 using WordPress. The Blog is curated and edited by a dedicated blog writer who picks up topics around freshwater science, policy and conservation. The Freshwater Blog provides an engaging, accessible resource on the key environmental issues for policymakers, students and the public discussing a wide range of environmental issues including effective freshwater ecosystem conservation, climate change, invasive species or citizen science. Up to now more than 470 posts were published attracting an increasing number of 80,000 to 110,000 visitors per year. Monthly hits reach 7,000 to 16,000 readers.

\section{FIP management structure, options for contribution and outlook}

The FIP is currently run by four European institutes focusing on freshwater biodiversity research: University of Natural Resources and Life Sciences, BOKU Vienna, Austria; University of Duisburg-Essen, Germany; Leibniz-Institute of Freshwater Ecology and Inland Fisheries (IGB), Berlin, Germany; Royal Belgian Institute of Natural Sciences, Brussels, Belgium. Many other institutes and scientists contribute occasionally to the FIP by providing data and information. The four partners, jointly forming the Governing Board of the FIP, are committed to further maintain and curate the platform. The joint "data focussed" FIP-FWBON Advisory Board supports decisions on both scientific and technical direction of the FIP as well as joint dissemination strategies for both reaching the freshwater community and raising the profile of freshwater biodiversity. It currently involves members of the Alliance for Freshwater Life, GBIF as well as eLTER.

In order to maintain and further extend the FIP, we highly welcome contributions for all FIP components from scientists, institutes, major research projects or other interested individuals from all over the world.
Most parts of the FIP are specifically meant to be extended over time.

Currently, three modes of contribution are possible:

- Supporting partners/projects They financially support the FIP, e.g. by funding web developments or specific parts of the platform. Supporting partners can use the FIP as a sustainable dissemination outlet for their own research. They become full members of the Advisory Board and are involved in future decisions about the FIP.

- Contributing partners/projects They submit research results to the FIP, e.g. maps for the Global Freshwater Biodiversity Atlas, occurrence data for the Freshwater Biodiversity Data Portal or metadata to the Freshwater Metadatabase. We also welcome fact sheets, policy briefs, how-to guides, videos or any other educational material. Contributing partners are mentioned in the respective contributors' section of the website.

- FIP friends They can request to be listed in the component "Freshwater networks \& projects", and links to their general websites or results/ deliverables will be established.

Since the establishment of the Freshwater Information Platform we have increased efforts to establish cooperation with various international networks. We are involved in the "Alliance for Freshwater Life", an interdisciplinary network of scientists, conservation professionals, educators, policy experts, and creatives, targeting global efforts for the protection of freshwater ecosystems, freshwater biodiversity and ecosystem services (Darwall et al., 2018). The FIP will be the central data hub for data and in-depth information related to the "data and synthesis" core area of the Alliance.

Additionally, we are involved in the establishment of GEO BON's Freshwater BON, which was officially endorsed in summer 2017. FWBON has agreed to use the Freshwater Information Platform for joint dissemination strategies aiming to reach the freshwater community, to raise awareness, and to enhance the recognition and knowledge of freshwater biodiversity. Concurrently, the platform will be further developed to form a central hub for compiling and integrating species distribution data, exploring possibilities for exchanging and publishing data from freshwater observatories and monitoring institutes. To realise 
this, we are currently setting up a Freshwater Network page with GBIF.

In conclusion, there is huge need for a research infrastructure like the FIP, ensuring a long-lasting legacy of freshwater biodiversity-related data and providing a central place for freshwater information allowing to assess the status of biodiversity as well as to raise awareness about freshwaters in general. We believe that the FIP is a good start in terms of building a network, supporting data mobilisation or acting as a hub for a multitude of components related to freshwater information. It will further be extended with data from a variety of research and applied projects with the long-term aim to develop a comprehensive knowledge base on freshwater biodiversity.

Acknowledgements Open access funding was provided by University of Natural Resources and Life Sciences Vienna (BOKU). We are very grateful to the former EU project officer Martin Sharman for initialising the BioFresh project and we thank all BioFresh partners for supporting the initial establishment of the Freshwater Information Platform. Further, we especially thank Robert Vogl, Jörg Freyhof, Will Darwall and Oliver Peters for their input and assistance while establishing the FIP. Additionally, we are grateful to the FIP advisory board members Peter Kristensen, Johannes Peterseil, Flavia Loures, Peter Brenton, Rob Guralnick, Dmitry Schigel, Andrea Hahn and André Heughebaert. Our work was supported by BioFresh (EU FP7, Contract Number 226874), MARS (EU FP7, Contract Number 603378), AQUACROSS (EU H2020, Grant Agreement Number 642317), GLANCE (German Federal Ministry of Education and Research; BMBF 01 LN1320A), FADA, AquaRES (Belspo BRAIN BR/132/A6/AQUARES), SAFRED (Belspo BRAIN BR/154/A6/SAFRED) and AMAZON FISH (ERANetLac, ELAC2014/DCC-0210).

Open Access This article is distributed under the terms of the Creative Commons Attribution 4.0 International License (http:// creativecommons.org/licenses/by/4.0/), which permits unrestricted use, distribution, and reproduction in any medium, provided you give appropriate credit to the original author(s) and the source, provide a link to the Creative Commons license, and indicate if changes were made.

\section{References}

Balian, E. V., H. Segers, C. Lévèque \& K. Martens, 2007. The freshwater animal diversity assessment: an overview of the results. Hydrobiologia 595: 627-637.

Belbin, L. \& K. J. Williams, 2016. Towards a national bioenvironmental data facility: experiences from the Atlas of Living Australia. International Journal of Geographical Information Science 30(1): 108-125.
Birk, S., W. Bonne, A. Borja, S. Brucet, A. Courrat, S. Poikane, A. Solimini, W. van de Bund, N. Zampoukas \& D. Hering, 2012. Three hundred ways to assess Europe's surface waters: an almost complete overview of biological methods to implement the Water Framework Directive. Ecological Indicators 18: 31-41.

Bueno, C. G., M. Moora, M. Gerz, J. Davison, M. Öpik, M. Pärtel, A. Helm, A. Ronk, I. Kühn \& M. Zobel, 2017. Plant mycorrhizal status, but not type, shifts with latitude and elevation in Europe. Global Ecology and Biogeography 26: 690-699.

Ceballos, G. \& P. R. Ehrlich, 2006. Global mammal distributions, biodiversity hotspots, and conservation. Proceedings of the National Academy of Sciences 103: 19374-19379.

Chavan, V. \& L. Penev, 2011. The data paper: a mechanism to incentivize data publishing in biodiversity science. BMC Bioinformatics BioMed Central Ltd 12: S2.

Chrzanowski C. \& T. Buijse, 2017. Freshwater Information System (FIS); Version: August 2017. http://fis. freshwatertools.eu/.

Cid, N., N. Bonada, S. Carlson, T. Grantham, A. Gasith \& V. Resh, 2017. High variability is a defining component of Mediterranean-climate rivers and their biota. Water 9(1): 52.

Clausnitzer, V., V. J. Kalkman, M. Ram, B. Collen, J. E. M. Baillie, M. Bedjanič, W. R. T. Darwall, K.-D. B. Dijkstra, R. Dow \& J. Hawking, 2009. Odonata enter the biodiversity crisis debate: the first global assessment of an insect group. Biological Conservation 142: 1864-1869.

Costello, M. J., 2009. Motivating online publication of data. BioScience 59: 418-427.

Darwall, W. R. T., K. G. Smith, D. Allen, M. B. Seddon, G. McGregor Reid, V. Clausnitzer \& V. J. Kalkman, 2009. Freshwater biodiversity: a hidden resource under threat. In Vié, J.-C., C. Hilton-Taylor \& S. N. Stuart (eds), Wildlife in a Changing World. IUCN, Gland: 43-54.

Darwall, W., V. Bremerich, A. De Wever, A. I. Dell, J. Freyhof, M. O. Gessner, H.-P. Grossart, I. Harrison, K. Irvine, S. C. Jähnig, J. M. Jeschke, J. J. Lee, C. Lu, A. M. Lewandowska, M. T. Monaghan, J. C. Nejstgaard, H. Patricio, A. Schmidt-Kloiber, S. N. Stuart, M. Thieme, K. Tockner, E. Turak \& O. Weyl, 2018. The alliance for freshwater life: a global call to unite efforts for freshwater biodiversity science and conservation. Aquatic Conservation: Marine and Freshwater Ecosystems 28: 1015-1022.

de Brouwer, J. H. F., M. H. S. Kraak, A. A. Besse-Lototskaya \& P. F. M. Verdonschot, 2019. The significance of refuge heterogeneity for lowland stream caddisfly larvae to escape from drift. Scientific Reports 9: 2140.

De Wever, A., A. Schmidt-Kloiber, M. O. Gessner \& K. Tockner, 2012. Freshwater journals unite to boost primary biodiversity data publication. BioScience 62(6): 529-530.

Desmet, P., 2013. Showing you this map of aggregated bullfrog occurrences would be illegal. "Reporting on open science" Blog. http://peterdesmet.com/posts/illegal-bullfrogs.html.

Dudgeon, D., A. H. Arthington, M. O. Gessner, Z.-I. Kawabata, D. J. Knowler, C. Lévêque, R. J. Naiman, A.-H. PrieurRichard, D. Soto, M. L. J. Stiassny \& C. A. Sullivan, 2006. Freshwater biodiversity: importance, threats, status and conservation challenges. Biological Reviews 81: 163-182. 
Feeley, K. J. \& M. R. Silman, 2011. The data void in modeling current and future distributions of tropical species. Global Change Biology 17: 626-630.

Fegraus, E. H., S. Andelman, M. B. Jones \& M. Schildhauer, 2005. Maximizing the value of ecological data with structured metadata: an introduction to Ecological Metadata Language (EML) and principles for metadata creation. Bulletin of the Ecological Society of America 86(3): 158-168.

Fornaroli, R., S. Calabrese, F. Marazzi, S. Zaupa \& V. Mezzanotte, 2019. The influence of multiple controls on structural and functional characteristics of macroinvertebrate community in a regulated Alpine river. Ecohydrology 12(2): e2069.

Garcia-Moreno, J., I. J. Harrison, D. Dudgeon, V. Clausnitzer, W. Darwall, T. Farrell, C. Savy, K. Tockner \& N. Tubbs, 2014. Sustaining freshwater biodiversity in the anthropocene. In Bhaduri, A., J. Bogardi, J. Leentvaar \& S. Marx (eds), The Global Water System in the Anthopocene. Springer, Cham: 247-270.

Gerovasileiou, V., A. Martínez, F. Álvarez, G. Boxshall, W. Humphreys, D. Jaume, L. Becking, G. Muricy, P. van Hengstum, S. Dekeyzer, W. Decock, B. Vanhoorne, L. Vandepitte, N. Bailly \& T. Iliffe, 2016. World Register of marine Cave Species (WoRCS): a new Thematic Species Database for marine and anchialine cave biodiversity. Research Ideas and Outcomes 2: e10451.

Haase, P., F. Pilotto, F. Li, A. Sundermann, A. W. Lorenz, J. D. Tonkin \& S. Stoll, 2019. Moderate warming over the past 25 years has already reorganized stream invertebrate communities. Science of The Total Environment 658: 1531-1538.

Hering, D., L. Carvalho, C. Argillier, M. Beklioglu, A. Borja, A. C. Cardoso, H. Duel, T. Ferreira, L. Globevnik, J. Hanganu, S. Hellsten, E. Jeppesen, V. Kodeš, A. L. Solheim, T. Nõges, S. Ormerod, Y. Panagopoulos, S. Schmutz, M. Venohr \& S. Birk, 2015. Managing aquatic ecosystems and water resources under multiple stress-an introduction to the MARS project. Science of The Total Environment 503-504: 10-21.

Jetz, W., J. M. McPherson \& R. P. Guralnick, 2012. Integrating biodiversity distribution knowledge: toward a global map of life. Trends in Ecology \& Evolution 27(3): 151-159.

Kattge, J., S. Díaz, S. Lavorel, I. C. Prentice, P. Leadley, G. Bönisch, E. Garnier, M. West-oby, P. B. Reich, I. J. Wright, J. H. C. Cornelissen, C. Violle, S. P. Harrison, P. M. Van Bodegom, M. Reichstein, B. J. Enquist, N. A. Soudzilovskaia, D. D. Ackerly, M. Anand, O. Atkin, M. Bahn, T. R. Baker, D. Baldocchi, R. Bekker, C. C. Blanco, B. Blonder, W. J. Bond, R. Bradstock, D. E. Bunker, F. Casanoves, J. Cavender-Bares, J. Q. Chambers, F. S. Chapin III, J. Chave, D. Coomes, W. K. Cornwell, J. M. Craine, B. H. Dobrin, L. Duarte, W. Durka, J. Elser, G. Esser, M. Estiarte, W. F. Fagan, J. Fang, F. FernándezMéndez, A. Fidelis, B. Finegan, O. Flores, H. Ford, D. Frank, G. T. Freschet, N. M. Fyllas, R. V. Gallagher, W. A. Green, A. G. Gutierrez, T. Hickler, S. I. Higgins, J. G. Hodgson, A. Jalili, S. Jansen, C. A. Joly, A. J. Kerkhoff, D. Kirkup, K. Kitajima, M. Kleyer, S. Klotz, J. M. H. Knops, K. Kramer, I. Kühn, H. Kurokawa, D. Laughlin, T. D. Lee, M. Leishman, F. Lens, T. Lenz, S. L. Lewis, J.
Lloyd, J. Llusià, F. Louault, S. Ma, M. D. Mahecha, P. Manning, T. Massad, B. E. Medlyn, J. Messier, A. T. Moles, S. C. Müller, K. Nadrowski, S. Naeem, Ü. Niinemets, S. Nöllert, A. Nüske, R. Ogaya, J. Oleksyn, V. G. Onipchenko, Y. Onoda, J. Ordonez, G. Overbeck, W. A. Ozinga, S. Patino, S. Paula, J. G. Pausas, J. Penuelas, O. L. Phillips, V. Pillar, H. Poorter, L. Poorter, P. Poschlod, A. Prinzing, R. Proulx, A. Rammig, S. Reinsch, B. Reu, L. Sack, B. Salgado-Negret, J. Sardans, S. Shiodera, B. Shipley, A. Siefert, E. Sosinski, J. F. Soussana, E. Swaine, N. Swenson, K. Thompson, P. Thornton, M. Waldram, E. Weiher, M. White, S. White, S. J. Wright, B. Yguel, S. Zaehle, A. E. Zanne \& C. Wirth, 2011. TRY—a global database of plant traits. Global Change Biology 17: 2905-2935.

Kraak, M. J., 2004. The role of the map in a Web-GIS environment. Journal of Geographical Systems 6: 83-93.

Lemm, J. U., C. K. Feld \& S. Birk, 2019. Diagnosing the causes of river deterioration using stressor-specific metrics. Science of The Total Environment 651: 1105-1113.

Lorenz, S. \& C. Wolter, 2019. Quantitative response of riverine benthic invertebrates to sediment grain size and shear stress. Hydrobiologia 834: 47-61.

Mack, L., H. E. Andersen, M. Beklioğlu, T. Bucak, R.-M. Couture, F. Cremona, M. T. Ferreira, M. G. Hutchins, U. Mischke, E. Molina-Navarro, K. Rankinen, M. Venohr \& S. Birk, 2019. The future depends on what we do todayprojecting Europe's surface water quality into three different future scenarios. Science of The Total Environment 668: 470-484.

Michener, W. K., 2006. Meta-information concepts for ecological data management. Ecological Informatics 1: 3-7.

Michener, W. K., 2015. Ten simple rules for creating a good data management plan. PLoS Computational Biology 11(10): e1004525.

Michener, W. K. \& M. B. Jones, 2012. Ecoinformatics: supporting ecology as a data-intensive science. Trends in Ecology \& Evolution Elsevier Ltd 27: 85-93.

Reid, A. J., A. K. Carlson, I. F. Creed, E. J. Eliason, P. A. Gell, P. T. Johnson, K. A. Kidd, T. J. MacCormack, J. D. Olden, S. J. Ormerod, J. P. Smol, W. W. Taylor, K. Tockner, J. C. Vermaire, D. Dudgeon \& S. J. Cooke, 2018. Emerging threats and persistent conservation challenges for freshwater biodiversity. Biological Reviews. https://doi.org/10. 1111/brv. 12480 .

Schinegger, R., L. Schülting, S. Schmutz, A. L. Solheim, S. Birk, C. Feld, D. Hering, M. Kuijper, C. Chrzanowski, T. Buijse, A. Borja, M. Venohr \& L. Globevnik, 2018. MARS recommendations on how to best assess and mitigate impacts of multiple stressors in aquatic ecosystems; accessible through http://www.mars-project.eu/files/ download/recommendations/MARS_Recommendations. pdf.

Schmidt-Kloiber, A. \& A. De Wever, 2018. Biodiversity and freshwater information systems. In: Schmutz, S. \& J. Sendzimir (eds), Riverine Ecosystem Management-Science for Governing Towards a Sustainable Future. Aquatic Ecology Series, Vol. 8. Springer, Cham: 391-412. ISBN SBN 978-3-319-73249.

Schmidt-Kloiber, A. \& D. Hering, 2015. www.freshwaterecology.info-an online tool that unifies, standardises and 
codifies more than 20,000 European freshwater organisms and their ecological preferences. Ecological Indicators Elsevier Ltd 53: 271-282.

Schmidt-Kloiber, A., S. J. Moe, B. Dudley, J. Strackbein \& R. Vogl, 2012. The WISER metadatabase: the key to more than 100 ecological datasets from European rivers, lakes and coastal waters. Hydrobiologia.

Schmidt-Kloiber, A., R. Vogl, A. De Wever \& K. Martens, 2014. Editorial-launch oft he freshwater metadata journal (FMJ). Freshwater Metadata Journal 1: 1-4.

Stattersfield, A. \& D. Capper, 2000. Threatened Birds of the World. Lynx Editions and Birdlife International, Barcelona and Cambridge.

Strayer, D. L. \& D. Dudgeon, 2010. Freshwater biodiversity conservation: recent progress and future challenges. Journal of the North American Benthological Society 29: 344-358.

Stuart, S. N., J. S. Chanson, N. A. Cox, B. E. Young, A. S. L. Rodrigues, D. L. Fischman \& R. W. Waller, 2004. Status and trends of amphibian declines and extinctions worldwide. Science 306: 1783-1786.

Tachet, H., P. Richoux, M. Bournaud \& P. Usseglio-Polatera, 2010. Invertébrés d'eau douce. Systématique, biologie, écologie. CNRS Editions: 1-607.

Tedersoo, L., M. Bahram, S. Põlme, U. Kõljalg, N. S. Yorou, R. Wijesundera, L. Villarreal Ruiz, A. M. Vasco-Palacios, P. Q. Thu, A. Suija, M. E. Smith, C. Sharp, E. Saluveer, A. Saitta, M. Rosas, T. Riit, D. Ratkowsky, K. Pritsch, K. Põldmaa, M. Piepenbring, C. Phosri, M. Peterson, K. Parts, K. Pärtel, E. Otsing, E. Nouhra, A. L. Njouonkou, R. H. Nilsson, L. N. Morgado, J. Mayor, T. W. May, L. Majuakim, D. J. Lodge, S. S. Lee, K. H. Larsson, P. Kohout, K. Hosaka, I. Hiiesalu, T. W. Henkel, H. Harend, L. D. Guo, A. Greslebin, G. Grelet, J. Geml, G. Gates, W. Dunstan, C. Dunk, R. Drenkhan, J. Dearnaley, A. De Kesel,
T. Dang, X. Chen, F. Buegger, F. Q. Brearley, G. Bonito, S. Anslan, S. Abel \& K. Abarenkov, 2014. Fungal biogeography. Global diversity and geography of soil fungi. Science 346(6213): 1256688.

Tedesco, P. A., O. Beauchard, R. Bigorne, S. Blanchet, L. Buisson, L. Conti, J.-F. Cornu, M. S. Dias, G. Grenouillet, B. Hugueny, C. Jézéquel, F. Leprieur, S. Brosse \& T. Oberdorff, 2017. A global database on freshwater fish species occurrence in drainage basins. Scientific Data 4: 170141.

Tydecks, L., V. Bremerich, J. Jentschke, G. E. Likens \& K. Tockner, 2016. Global Database on Biological Field Stations a pivotal infrastructure for environmental research, education and public information. Limnology and Oceanography Bulletin 25: 88.

van Vliet, M. T. H., F. Ludwig \& P. Kabat, 2013. Global streamflow and thermal habitats of freshwater fishes under climate change. Climatic Change 121: 739-754.

WWF. 2018. Living planet report-2018: aiming higher. In: Grooten, M. and Almond, R.E.A. (eds). WWF, Gland.

WWF. 2019. Water Risk Filter 5.0-Water Risk Assessment Methodology. WWF Water Risk Filter-Data \& Methods, waterriskfilter.panda.org/en/Explore/DataAndMethod.

Zagmajster, M., D. Eme, C. Fišer, D. Galassi, P. Marmonier, F. Stoch, J.-F. Cornu \& F. Malard, 2014. Geographic variation in range size and beta diversity of groundwater crustaceans: insights from habitats with low thermal seasonality. Global Ecology and Biogeography 23: $1135-1145$.

Publisher's Note Springer Nature remains neutral with regard to jurisdictional claims in published maps and institutional affiliations. 